\title{
The Development of Intelligent Computer-Assisted Efficient Using the Tree Data Structure: The Case Study of the Religion Societies and Culture Subject
}

\author{
O. Thinnukool and K. Champhorm
}

\begin{abstract}
The constructions of Intelligent Computer Assistance-Instruction (iCAI) are practically less use in Thai education because they are required programming skills. The purposes of this research are developing, testing and measuring the efficiency of $\mathrm{iCAI}$, especially in the religion societies and culture subject. It is constructed with the program that is supported. The tree data structure is able to respond with individual varieties. The stratified random sampling technique has been applied to measure the proposed iCAI according to sixth-grade students data. An instrument test by population is classified with GPA. The samples divided into three groups; smart, medium and low. To examine the efficiency of the iCAI lessons, The 80/80 standard criterion was used. A result of the study is 84.21/83.33, which is higher than the preset criterion of $80 / 80$ standard it can be the theoretically substituted regular lesson. The students who studied by using iCAI had higher learning effectiveness than the students who studied in normal learning program at 0.1 of statistical significance.
\end{abstract}

Index Terms-Intelligent Computer Assistance-Instruction (iCAI), Tree Data Structure, Efficiency of a Lesson.

\section{INTRODUCTION}

In this study, a tree structure is employed. It represents on the movement of node in binary tree to design lesson. The nodes are representation lesson of frames and each node also provides extra frames and new knowledge frames. Knowledge evaluation by giving the test or question to learners and bring outcomes to be the traveling condition toured around each node. It is the same style of process likes branching programming, however, the tree structure provides more special lesson's writer such as the ability of ranking, presenting, and interaction between the lessons and the learners. The efficiency tryout was done by getting $80.00 \%-83.23 \%$, an acceptable rate that generated the learning program for Matthayom 5. The sampling with three tryouts: individually $(1: 1: 1)$, small groups divided (5:5:5), and big groups divided (10:10:10). The outcome of efficiency tryout would be 2 indicators to confirm that this iCAI was produced upon the tree data structure could be used or not.

Manuscript received May 2, 2012; revised August 20, 2012.

O. Thinnukool is with Prince of Songkhla University (webppu@hotmail.com).

$\mathrm{K}$. Champhorm is with department of Education Communication and Technology Thaksin University.

\section{RELATED THEORIES}

\section{A. Kinds of Program Lesson}

Nowadays, computer assisted instruction (CAI) is very important instruction media that can help to manage the studying programs and can help learners to repeat lessons by themselves and no need to rely on a teacher.[1],[2] There are three kinds of CAI. Linear Programming, the leaner must be studied unit by unit according to the step is set and can't ignored even one unit. Branching Programming is the lesson that have divided content frame, it is not linear arrangement. The learners will be perceived in different content according to the studying levels. Combination Programming is the lesson that design to combine between linear programming and branching programming. This program provides a chance to respond to either linear or branch programming.

\section{B. Formats of Computer Assisted Instruction}

There are a number of Computer Assisted Instruction are designed to help teaching activities and can be divided as the followings.[3]-[5]

- Teaching content programming: it is the lesson that uses to teach in each subject. It is suitable for rules and theories presenting or use to learn the strategy for problem solving.

- Practicing programming: this program will be presented in terms of questions in different methods and formats such as multiple choices style. It concentrates on testing and knowledge repeating.

- Hypothesis situation programming: the lesson will be presented in terms of hypothesis situation that act nearly with real situation and the learner can relate it. This format of program can provide the safety, reduce cost, and can help the learner to have more understanding in the lesson.

- Gaming program: this program will encourage the learner to reach their need by many ways such as challenging, curiosity, and/or imagination. The content will be inserted into the games and can encourage the student to enjoin in each lesson.

- Testing programming: is a program that uses to measure the level of knowledge of learner, it sometime cannot be measured with general methods such as the testing of hypothesis aeronautical program of pilot and etc.

\section{Intelligent Computer Assisted Instruction (iCAI)}

The intelligent computer assisted instruction (iCAI) can be divided into many kinds of contents and its system is 
flexible in different learning environments [6]. iCAI should include the following:

1) Knowledge of teaching content

2) Leaner's knowledge

3) Knowledge of teaching strategy

4) Knowledge of strategic management to support students need

Moreover, there are many important components such as the practicing to repeat the content, suggestion, learning facility [7], concentration on the progress of student learning level in order to set the suitable teaching activity [8] etc. This program is designed to have different levels of difficulties serve to different person knowledge [9],[10] and also provides many alternative ways in term of knowledge presentation to respond different needs of student. [11] The crucial point of the lesson is Externalization. It is the way to extract the knowledge and bring into learning frames of the learners. Tree data structure will be used to lay down the content in each frame and build up the content link and direction. Furthermore, the structure also helps to rank the content for presentation step. Thus, Tree data structure is the one suitable method that uses to plan the knowledge frame according to learning ability of students.

\section{Lesson Link: Tree Structure}

Computer assisted instruction can be built up by using synthesis stories board with theory of knowledge frame lay down into lesson frames (they were represented by nodes in tree structure) as shown in Fig. 1.

In the Fig. 1, node $1^{\text {st }}$, frame A-1 represented which contains the main frame the lesson content or question. It is the tool to measure the knowledge and understanding of the learner and analyze them into next different node. For example, when the learner can gather corrected answer, then they can pass to node $2^{\text {nd }}$ (Circle No. 2) names A-2 but if they do the wrong answer they need to go next to node $4^{\text {th }}$ (frame $4^{\text {th }}$ ) which is the extra knowledge frame. From frame A-2, if the learner still gets the corrected answer, they will go next to frame A-3 and A-4 accordingly. In the other hand, if the learner still gets the wrong answer, they must be jumped only in extra knowledge frame and new knowledge frame.

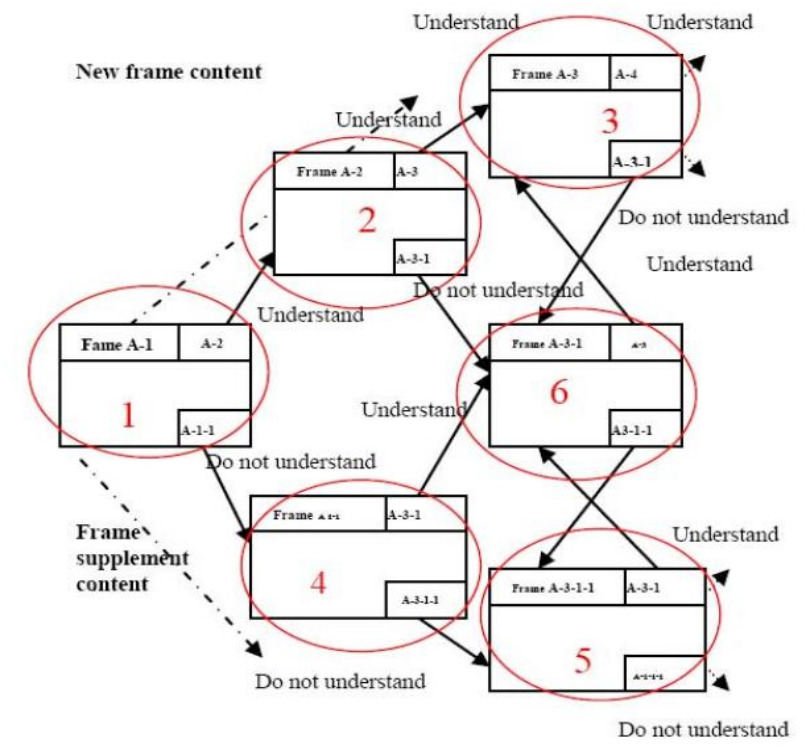

Fig. 1. Link of knowledge frame

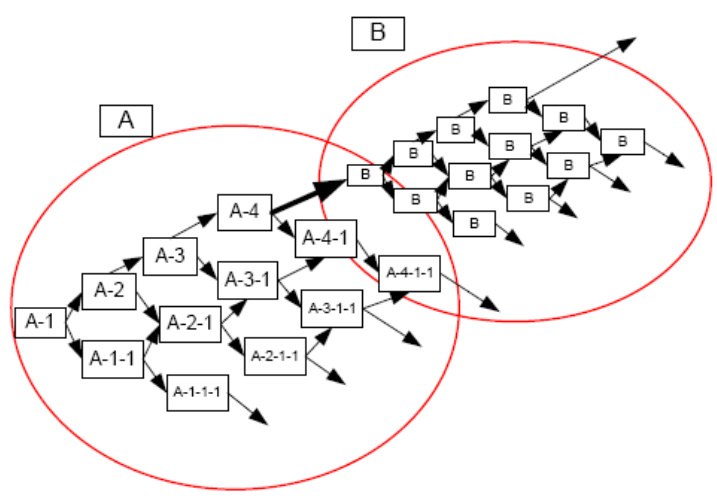

Fig. 2. Link of knowledge frame

From the above figures, they present that the frames were represented by combination of nodes content frames and tests such as frame A-1. In frame A-1 that included lesson content and the questions to measure learner's understanding. The outcome would be analyzed and passed the learner to next node upon the understanding condition of the learner. Namely, if their understanding is higher, they will pass to higher level node and get new content frame. However, it they make the wrong answer in that higher level node, they must be dropped down to lower level node again lead to the extra knowledge frame that prepare the explanation and contest to support the main frame. Fig. 2, it was presents the movement of lesson content such as A was showing contents, learning units, and physical conditions. Additionally B present to economic content. Regarding all above explanation presented by Fig. 1 and Fig. 2, we can see that all contents can be links in order to set the right content serve to the right learner in each level. Further more, iCAI's designer can manage and rank the lesson content easily.

\section{E. Efficiency Tryout of Computer Assisted Instruction.}

Efficiency criteria $80 / 80$ is the level of efficiency of CAI that set the learner is in the level of satisfaction, it is set by iCAI's producer. The efficient CAI is suitable to use in teaching activity, namely, efficient iCAI is evaluated by 2 performances of learner including continuously behavior (processing) and final behavior (outcome). E1 will be presented as efficient value (processing efficiency) and E2 (outcome efficiency) can be calculated from the formulas [1], [2], [4] When

$$
\begin{aligned}
& E_{1}=\left[\frac{\sum X}{N / A}\right] \times 100 \\
& E_{2}=\left[\frac{\sum F}{N / B}\right] \times 100
\end{aligned}
$$

E1 = the average point from correct answer in each lesson testing, present in term of percentage

E2 = the average point from correct answer of all post- test, present in term of percentage

$\sum \mathrm{X}=$ total point of correct answer from lesson testing

$\sum \mathrm{F}=$ total point from correct answer from post-test

$\mathrm{A} \quad=$ full marks of lesson testing

$\mathrm{B}=$ full marks of post-test

$\mathrm{N} \quad=$ total of student 


\section{LESSON OF ICAI}

The researcher produced computer assisted instructions from program are support by presenting of the theory of tree structure. The learner can choose the lesson because of the designing of graphic user interface (GUI), interaction and immediate feedback that serve the lesson presentation then. The lessons include the content of religion societies and culture subject. In the final part of all lesson content will attach post-test to measure the understanding of the learner. All point results from the test will be used to measure the efficiency of lesson.

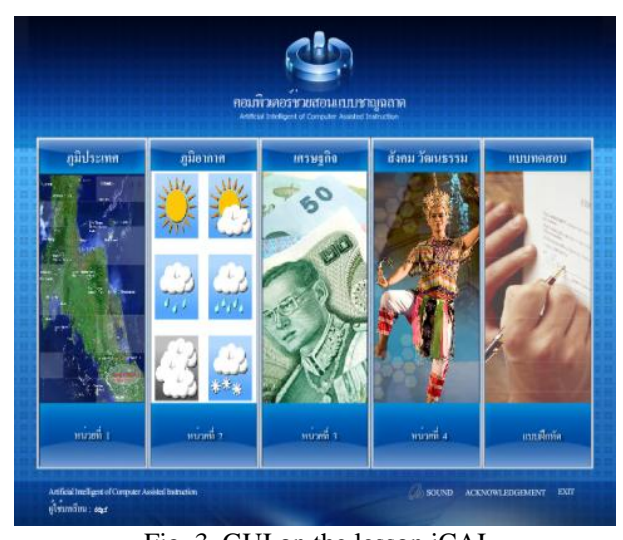

Fig. 3. GUI on the lesson iCAI

The graphic user interface (GUI) was presenting in Fig. 3, a main page enters to the content. Knowledge presentation of the content frame in the lesson was presenting in Fig. 4. Fig. 5 was presenting the frame after content presentation, the sound of lecture and the frame as same as figure 4 will be given if the answer that the learner choose is not correct.

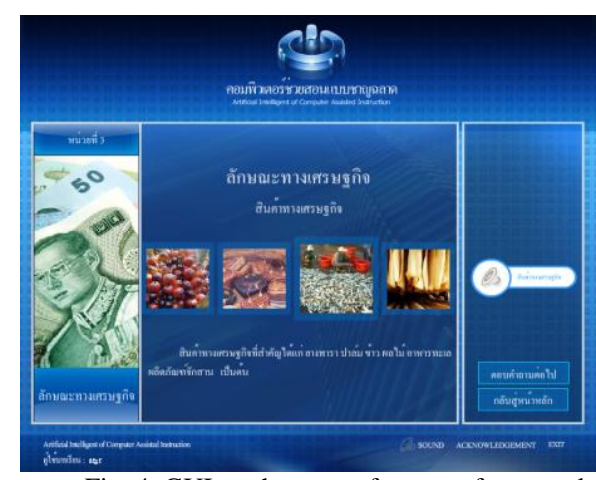

Fig. 4. GUI on the page of content frame and knowledge presentation

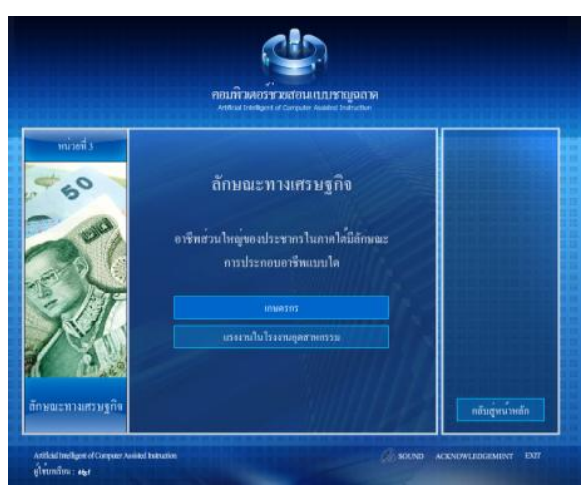

Fig. 5. GUI on the page to testing questions

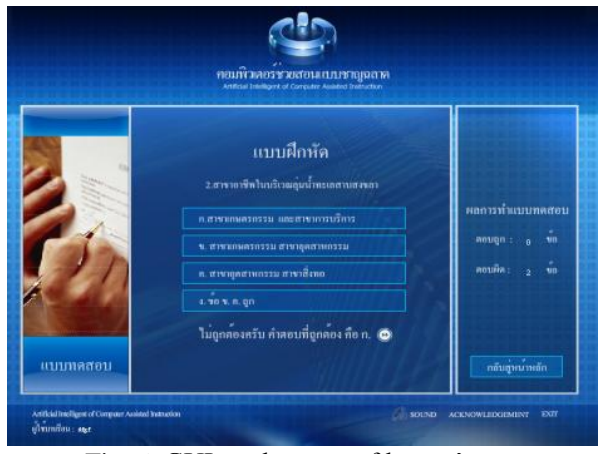

Fig. 6. GUI on the page of lesson's test

However, the content in this frame will support primary knowledge and match with the content of main frame. In the same time, the immediate feedback will be answered from the learner to the lesson and pass to content upon the link of knowledge frame was set. Frame of the lesson's test after finishing of each learning unit was shown in Figure 6. There were 10 questions provided to the learner and the research kept the point to analyzed the percentage, E1 (the efficiency of lesson E1/E2), in order to find out the value of efficient according to the rule of $80 / 80$ of the lesson.

\section{COMPUTER ASSISTANT IstruCtion's EFFICENCY TRYOUT}

\section{A. Sampling Group for Efficiency Tryout}

In this study, marks from religion societies and culture subject's examination would be used as a tool to find out the efficiency of the lesson. The sampling groups of students were divided into smart, medium, and low level. The sampling was done by stratified random sampling technique, the students were grouped into smart, medium, and low level by ranking at 4.00-3.00, 2.99-2.50, and 2.492.00 accordingly. Then, simple random sampling without replacement technique was used by numbering all population and then chose by drawing. The samplings were not repeated again with the population that already received the sampling in order to get the highest efficiency of lesson as below:

TABLE I: THE SAMPLING GROUP FOR EFFICENCY TRYOUT

\begin{tabular}{ccccc}
\hline \hline \multirow{5}{*}{ Group } & \multicolumn{3}{c}{ Level of Sample } & Total \\
& Smart & Medium & Low & \\
\hline Individual & 1 & 1 & 1 & 3 \\
Small & 5 & 5 & 5 & 15 \\
Big & 10 & 10 & 10 & 30 \\
Total & 16 & 16 & 16 & 48 \\
\hline \hline
\end{tabular}

\section{B. Efficiency of Intelligent Computer Assisted Instruction}

The efficiency was detected by the lesson of iCAI that performed with sampling group as shown in Table II.

In table II, the researcher did first time efficiency tryout, individually $1: 1: 1$, by using the lesson of CAI and post-test. The average point was $68.34 \% / 74.45 \%$, it was lower than minimum criteria of CAI's lesson (acceptable efficiency was 80/80). Then, the researcher improved the outcome of first time tryout by asking the learner's comments and 
correcting the content in order to add more knowledge and understanding. After the content was improved, second time of tryout was started (small groups divided 5:5:5) to find out small group efficiency. The average point was $80.17 / 80.23$ that passed the criteria was set. The researcher improved again by correcting learning frame and adding more content. Furthermore, the comment from small sampling group was analyzed and used to improve the content too. After second time of tryout was passed and improved, the researcher did third time of efficiency tryout (big groups divided 10:10:10). 81.00\% / 83.23\% was the average point in third time and can be used in the experiment field.

TABLE II: EFICIENCY OF COMPUTER ASSISTED INSTRUCTION

\begin{tabular}{|c|c|c|c|c|c|c|}
\hline & Score & & 尽 & $\begin{array}{l}\mathbb{T} \\
\Xi \\
\tilde{D} \\
0 \\
0\end{array}$ & تृ & 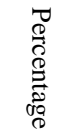 \\
\hline \multirow{2}{*}{$\begin{array}{l}\text { Individual } \\
\text { Group }\end{array}$} & $\begin{array}{l}\text { Exercises } \\
\text { class }\end{array}$ & during & 3 & 40 & $\begin{array}{c}27.3 \\
4\end{array}$ & 68.34 \\
\hline & Postte & & 3 & 30 & $\begin{array}{c}22.3 \\
4\end{array}$ & 74.45 \\
\hline \multirow{2}{*}{$\begin{array}{l}\text { Small } \\
\text { Group }\end{array}$} & $\begin{array}{l}\text { Exercises } \\
\text { class }\end{array}$ & during & 15 & 40 & $\begin{array}{c}32.0 \\
6\end{array}$ & 80.17 \\
\hline & Postte & & 15 & 30 & $\begin{array}{c}24.0 \\
7\end{array}$ & 80.23 \\
\hline \multirow{2}{*}{ Big Group } & $\begin{array}{l}\text { Exercises } \\
\text { class }\end{array}$ & during & 30 & 40 & 32.4 & 81.00 \\
\hline & Postte & & 30 & 30 & $\begin{array}{c}24.9 \\
7\end{array}$ & 83.23 \\
\hline
\end{tabular}

\section{Field Experiments}

Populations Population: 210 students in Matthayom 5 of Photongpratan Kiriwat School who were studying religion societies and culture subject.

Sample stratified random sampling technique was used as the sampling method by dividing the students into 3 groups, smart, medium, and low based on GPA rate. Then, simple random sampling would be used in next step in order to separate 60 students into each group, The comparison between the experimental group learning by with iCAI and group learning by traditional learning. Divided the students were selected by stratified to experimental and control groups as Table III.

TABLE III: THE SAMPLE SIZES OF EXPERIMENTAL GROUP AND CONTROL GROUP

\begin{tabular}{lcccc}
\hline \hline & \multicolumn{3}{c}{ Level of Sample } & \\
Experimental Patterns & smart & medium & low & Total \\
\hline Learning by iCAI & 10 & 10 & 10 & 30 \\
Traditional Learning & 10 & 10 & 10 & 30 \\
$\quad$ Total & 20 & 20 & 20 & 60 \\
\hline \hline
\end{tabular}

In fieldwork to compare student's grade between the students who study by using iCAI (experiment group) and the students in normal class (controlled group), a researcher divided the students from each group of Table III into 6 classrooms. With equal of time, period and content, there were 3 rooms were studied by iCAI and another 3 classrooms were provided by normal program.

\section{SUMMARY}

\section{A. Experimental results}

The results from tests of 30 questions that validated by specialist content. To sample the 2 groups were compared with the results of statistical analysis (Independent Samples Test) by $\mathrm{R}$ program were showed in below:

TABLE IV: THE DIFFERENCE BETWEEN LEARNING BY ICAI AND TRADITIONAL LEARNING WITH R PROGRAM

\begin{tabular}{lcccc}
\hline \hline & n & Mean & Std. Deviation & $\begin{array}{c}\text { Std. Error } \\
\text { Mean }\end{array}$ \\
\hline iCAI & 30 & 22.33 & 2.171 & 0.474 \\
$\begin{array}{l}\text { Traditional } \\
\text { Learning }\end{array}$ & 30 & 18.87 & 2.460 & 0.626 \\
\hline \hline
\end{tabular}

TABLE V: THE DIFFERENCE BETWEEN LEARNING BY ICAI AND TRADITIONAL LEARNING WITH STATISTICAL BY T-TEST

\begin{tabular}{cccccc}
\hline \hline \multicolumn{7}{c}{ t-test } \\
\hline \multirow{2}{*}{0.483} & Sig. & $\mathrm{t}$ & $\mathrm{df}$ & $\begin{array}{c}\text { Sig.(2- } \\
\text { tailed) }\end{array}$ & $\begin{array}{c}\text { Std. } \\
\text { Error }\end{array}$ \\
& \multirow{2}{*}{0.490} & 5.788 & 58 & 0.000 & 3.47 \\
& & 5.788 & 57.117 & 0.000 & 3.47 \\
\hline \hline
\end{tabular}

The experiment was resulted by using 30 questions that was analyzed by difficulty, discrimination, and reliability, tested with 2 groups of students (iCAI and normal program). Statistic program, t-test independent, was used in order to find out each group's differences with the same variance. As the result, the students who studied by using iCAI would have higher grade than the students who studied in normal learning program with average 22.33 (Table IV andTable V) accordingly or at 0.1 statistical significance of differentiation.

The researcher used the content, the efficiency of iCAI in subject of religion social and culture related with the lesson on geographic southern part of Thailand, designed the lesson then leaded to measurement of efficiency tryout by using the points from each lesson and post-test examination to analyze the efficiency. $80.00 \%-83.23 \%$ was the percentage that generated the learning program for Matthayom 5 in above topic. The aforementioned learning content came from the efficiency of iCAI based on the theory of tree data structure; the outcome of iCAI must be acceptable in order to serve the differentiation of learners. Further more, the program was designed with 2 directions of condition, it generated more alternatives and learning frames for the learner resulted more understanding in content and lesson.

\section{SugGestion}

The efficiency of all kind iCAI tryout must be written down the accurate main structure or storyboard according to the content and course. All lessons must be checked by professionals in order to generate the highest accurate content and tool before the experiment of efficiency tryout. More responsibility in differentiation of the learner can improve if the iCAI that generate from tree data structure can provide more nodes (learning frame) and produced more alternatives. In the same time, programming 
knowledge can help to support the activity of leaner evaluation leaded to more intelligent lesson. Furthermore, the testing of the relative of Time Dimension for study, the teaching planning, and/or the relative between student and lesson can also support the way to generate the knowledge in order to develop of iCAI lessons in each kind lead to the improvement of leaning management.

\section{ACKNOWLEDGMENT}

The author would like to thanks Assistant Prof. Thakerng Wongsirichot, Department of ICT Faculty of Science PSU. for review this paper extensive and insightful discussions and comments on the paper.

\section{REFERENCES}

[1] P. Mueama, Design principles and the creation of computer assisted instruction program Authorware Professional 5, Department of Educational Technology. Faculty of Education Prince of Songkla University, 2011.

[2] C. Promwong, SomChow Nate and SudaSinsakool. Teaching System, Bangkok: Chulalongkorn University, 2520, pp25-18, 2010.

[3] B. C. Sisaart, Basic research: Type No. 2. Bangkok: Suveeriyasan, 2535, pp.12-17, 2010.

[4] T. Laohapoonrungsee. Computer-assisted instruction. Bangkok: Wong grom Production, 2541, 2010.

[5] W. Prasarnsoy. Computer Assisted Instruction: Innovation for Education. Bangkok: VJ Printing, 2543.

[6] S. Suebnukarn and P. Haddawy, "A collaborative intelligent tutoring system for edictal problem- base Learning," in Proc. the 9th International Conference on Intelligent User interface, Madeira, Portugal, pp.14-22, 2004.
[7] K. VanLehn, C. Frasson, and G. Gauthier Eds. "Intelligent Tutoring Systems" in Proc. of 5th International Conference on Intelligent tutoring Systems, Lecture Notes in Computer Science, 2000.

[8] F. C. Robert and O. C. Park, "Intelligent computer-Assisted Instruction : An explanation and overview," In Expert System and intelligent computer-aided instruction, New Jersey: Educational technology Publication, 1991.

[9] Beverly Woolf and Morgan Kauffman, Building intelligent interactive tutors, 2008.

[10] J. R. Hartley and D. H. Sleeman, .Toward intelligent teacher systems," International Journal of Man-Machines Studies, pp. 215-236, 1973.

[11] N. D. Liver good, "Computer-assisted instruction to Intelligent tutoring systems," Journal of artificial Intelligence in Education, pp. 39-50, 1991.

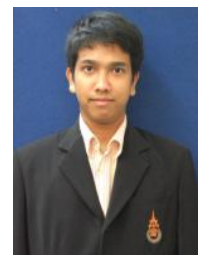

Orawit Thinnukool was born in Songkhla, Thailand in 1987. The author has received Bachelor of Science (Information Communication and Technology) Prince of Songkhla University Hatyai Campus, He has also received Master of Educational (Education Communication and Technology) from THAKSIN University. Now he is studying in Ph.D. (Research Methodology) Prince of Songkhla University.

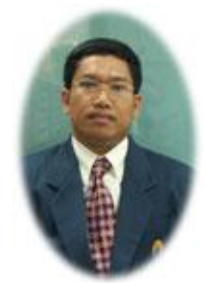

Kritsanaphon Champhom was born in Songkhla, Thailand in 1961. He has also received Doctoral of Educational (Education Communication and Technology) from Ramkamhang University. Now he was lecturer in department of Education Communication and Technology Thaksin University. 